\title{
On convergence of an implicit algorithm for multivalued mappings in Banach spaces
}

\author{
Isa Yildirim
}




\title{
ON CONVERGENCE OF AN IMPLICIT ALGORITHM FOR MULTIVALUED MAPPINGS IN BANACH SPACES
}

\author{
ISA YILDIRIM
}

Received 19 March, 2012

\begin{abstract}
In this paper, we introduce an implicit algorithm for finding a common fixed point of two quasi-nonexpansive multivalued mappings in Banach spaces. We also prove some convergence theorems for the purposed algorithm under some control conditions.

2010 Mathematics Subject Classification: 47H09; 47H10

Keywords: quasi-nonexpansive multivalued mappings, nonexpansive multivalued mappings, common fixed point, convergence theorems, Banach spaces
\end{abstract}

\section{INTRODUCTION}

Let $X$ be a Banach space. A subset $E \subset X$ is called proximinal if for each $x \in X$, there exists an element $y \in E$ such that

$$
d(x, y)=\inf \{\|x-z\|: z \in E\}=d(x, E) .
$$

It is known that every closed convex subset of a uniformly convex Banach space is proximinal.

We denote by $C B(E), K(E)$ and $P(E)$ the collection of all nonempty closed bounded subsets, nonempty compact subsets, and nonempty proximal bounded subsets of $E$ respectively. The Hausdorff metric $H$ on $C B(X)$ is defined by

$$
H(A, B)=\max \left\{\sup _{x \in A} d(x, B), \sup _{y \in B} d(y, A)\right\}
$$

for all $A, B \in C B(X)$.

Let $T: X \longrightarrow 2^{X}$ be a multivalued mapping. An element $x \in X$ is said to be a fixed point of $T$, if $x \in T x$. Denote by $F(T)$ the set of fixed points of $T$ and by $F:=F(S) \cap F(T)$ the set of common fixed points of the mappings $S$ and $T$.

Definition 1. A multivalued mapping $T: X \longrightarrow C B(X)$ is called

(i) contraction if there exists a constant $k \in[0,1)$ such that for any $x, y \in X$,

$$
H(T x, T y) \leq k\|x-y\|,
$$


(ii) nonexpansive if

$$
H(T x, T y) \leq\|x-y\|
$$

for all $x, y \in X$,

(iii) quasi-nonexpansive if $F(T) \neq \varnothing$ and

$$
H(T x, T p) \leq\|x-p\|
$$

for all $x \in X$ and all $p \in F(T)$.

It is clear that every nonexpansive multivalued mappings $T$ with $F(T) \neq \varnothing$ is quasi-nonexpansive. But there exist quasi-nonexpansive mappings that are not nonexpansive, see [13]. It is known that if $T$ is a quasi-nonexpansive multivalued mappings, then $F(T)$ is closed.

The fixed point theory of multivalued nonexpansive mappings is much more complicated and diffucult than the corresponding theory of single-valued nonexpansive mappings. However, some classical fixed point theorems for single-valued nonexpansive mappings have already been extended to multivalued mappings.

The study of fixed points for multivalued contractions and nonexpansive mappings using the Hausdorff metric was initiated by Markin [7] (see also [8]). Later, an interesting and rich fixed point theory for such maps was developed which has applications in control theory, convex optimization, differential inclusion and economics (see, [2] and references cited therein). Moreover, the existence of fixed points for multivalued nonexpansive mappings in uniformly convex Banach spaces was proved by Lim [6].

In 1999, Sahu [11] obtained the strong convergence theorems of the nonexpansive type and nonself multivalued mappings for the following algorithm:

$$
x_{n}=t_{n} u+\left(1-t_{n}\right) y_{n}, \quad n \geq 0,
$$

where $y_{n} \in T x_{n}, u \in E, t_{n} \in(0,1)$ and $\lim _{n \rightarrow \infty} t_{n}=0$. He proved that $\left\{x_{n}\right\}$ converges strongly to some fixed points of $T$. Xu [15] extended Theorem 1.3 to a multivalued nonexpansive nonself mapping and obtained the fixed theorem in 2001.

Recently, He et al. [3] obtained common fixed points of a nonexpansive multivalued mapping $T: E \longrightarrow C B(E)$ satisfying certain conditions. To achive this, they employed the following Mann type implicit algorithm:

$$
\left\{\begin{array}{l}
x_{0} \in E, \\
x_{n}=\alpha_{n} x_{n-1}+\left(1-\alpha_{n}\right) y_{n}, \quad n \geq 1,
\end{array}\right.
$$

where $y_{n} \in T x_{n}$ and $\alpha_{n} \in[0,1]$. They proved some strong convergence theorems of the sequence $\left\{x_{n}\right\}$ defined by (1.2) for nonexpansive multivalued mappings in Banach spaces.

In this paper, we introduce an iterative algorithm for common fixed points of two quasi-nonexpansive multivalued mappings. Let $S, T: E \longrightarrow C B(E)$ be two quasinonexpansive multivalued mappings with common fixed point $p$. Our algorithm is as 
follows:

$$
\left\{\begin{array}{l}
x_{0} \in E, \\
x_{n}=\alpha_{n} x_{n-1}+\beta_{n} y_{n}+\gamma_{n} z_{n}, \quad n \geq 1,
\end{array}\right.
$$

where $y_{n} \in S x_{n}, z_{n} \in T x_{n}$ and $\left\{\alpha_{n}\right\},\left\{\beta_{n}\right\}$ and $\left\{\gamma_{n}\right\}$ are sequence of numbers in $[0,1]$ satisfying $\alpha_{n}+\beta_{n}+\gamma_{n}=1$.

Using the implicit algorithm (1.3), we prove some weak and strong convergence theorems for approximating common fixed points of two quasi-nonexpansive multivalued mappings in a uniformly convex Banach space. These results improve and extend the corresponding results of Khan et al. [5], Soltuz [14] and Xu and Ori [16] to the case of multivalued mappings. Our results also improve the corresponding results of He et al. [3] for two quasi-nonexpansive multivalued mappings.

We shall use the condition $S p=T p=\{p\}$ for any $p \in F:=F(S) \cap F(T)$ in order to prove main results of this paper. Below is an example of two quasinonexpansive multivalued mappings satisfying this condition.

Example 1. Let $E=[0,1]$ be endowed with the Euclidean metric. Let $S, T: E \longrightarrow$ $C B(E)$ be defined by $S x=[0, x]$ and $T x=\left[0, \frac{x}{2}\right]$. Thus

$$
\begin{aligned}
H(S x, S y) & =\max \{|x-y|, 0\} \\
& \leq|x-y| .
\end{aligned}
$$

In a similar way, we obtain that

$$
\begin{aligned}
H(T x, T y) & =\max \left\{\left|\frac{x}{2}-\frac{y}{2}\right|, 0\right\} \\
& \leq\left|\frac{x}{2}-\frac{y}{2}\right| \\
& \leq|x-y| .
\end{aligned}
$$

Since $F(S)=[0,1]$ and $F(T)=\{0\}$ are nonempty sets, $S$ and $T$ are quasi-nonexpansive multivalued mappings and $S p=T p=\{p\}$ for any $p \in F$.

\section{Preliminaries}

A Banach space $X$ is called uniformly convex if for each $\epsilon>0$ there is a $\delta>0$ such that for $x, y \in X$ with $\|x\|,\|y\| \leq 1$ and $\|x-y\| \geq \epsilon,\|x+y\| \leq 2(1-\delta)$ holds. The modulus of convexity of $X$ is defined by

$$
\delta_{X}(\epsilon)=\inf \left\{1-\left\|\frac{1}{2}(x+y)\right\|:\|x\|,\|y\| \leq 1,\|x-y\| \geq \epsilon\right\},
$$

for all $\epsilon \in[0,2] . X$ is said to be uniformly convex if $\delta_{X}(0)=0$, and $\delta(\epsilon)>0$ for all $0<\epsilon \leq 2$. 
A Banach space $X$ is said to satisfy Opial's condition [9] if for any sequence $\left\{x_{n}\right\}$ in $X, x_{n} \rightarrow x$ implies that

$$
\limsup _{n \rightarrow \infty}\left\|x_{n}-x\right\|<\limsup _{n \rightarrow \infty}\left\|x_{n}-y\right\|
$$

for all $y \in X$ with $y \neq x$.

Examples of Banach spaces satisfying this condition are Hilbert spaces and all $l^{p}$ spaces $(1<p<\infty)$. On the other hand, $L^{p}[0,2 \pi]$ with $1<p \neq 2$ fail to satisfy Opial's condition.

A multivalued mapping $T: E \rightarrow P(X)$ is called demiclosed at $y \in E$ if for any sequence $\left\{x_{n}\right\}$ in $E$ which is weakly convergent to an element $x$ and $y_{n} \in T x_{n}$ with $\left\{y_{n}\right\}$ converges strongly to $y$, we have $y \in T x$.

A multivalued mapping $T: E \rightarrow C B(E)$ is said to be satisfy Condition $(A)$ if there exists a nondecreasing function $f:[0, \infty) \rightarrow[0, \infty)$ with $f(0)=0, f(r)>0$ for all $r \in(0, \infty)$ such that

$$
d(x, T x) \geq f(d(x, F(T))
$$

for all $x \in E$. Khan and Fukhar-ud-din [4] introduced the so-called Condition $\left(A^{\prime}\right)$ and gave a bit improved version in [1]. The following is the multivalued version of Condition $\left(A^{\prime}\right)$.

Two multivalued nonexpansive mappings $S, T: E \rightarrow C B(E)$ where $E$ a subset of $X$, are said to satisfy Condition $\left(A^{\prime}\right)$ if there exists a nondecreasing function $f$ : $[0, \infty) \rightarrow[0, \infty)$ with $f(0)=0, f(r)>0$ for all $r \in(0, \infty)$ such that

$$
\text { either } d(x, T x) \geq f(d(x, F(S) \cap F(T)) \text { or } d(x, S x) \geq f(d(x, F(S) \cap F(T))
$$

for all $x \in E$. The Condition $\left(A^{\prime}\right)$ reduces to the Condition $(A)$ when $S=T$.

Next, we state the following useful lemma.

Lemma 1 ([12]). Suppose that $E$ is a uniformly convex Banach space and $0<$ $p \leq t_{n} \leq q<1$ for all positive integers $n$. Also suppose that $\left\{x_{n}\right\}$ and $\left\{y_{n}\right\}$ are two sequences of $E$ such that $\limsup _{n \rightarrow \infty}\left\|x_{n}\right\| \leq r, \limsup _{n \rightarrow \infty}\left\|y_{n}\right\| \leq r$ and $\lim _{n \rightarrow \infty}\left\|t_{n} x_{n}+\left(1-t_{n}\right) y_{n}\right\|=r$ hold for some $r \geq 0$. Then $\lim _{n \rightarrow \infty}\left\|x_{n}-y_{n}\right\|=0$.

\section{MAin Results}

In order to prove some strong and weak convergence theorems, we need the following lemmas. By means of the iterative algorithm (1.3), we shall prove the following lemmas.

Lemma 2. Let $X$ be a normed space and $E$ be a nonempty closed convex subset of $X$. Let $S, T: E \rightarrow C B(E)$ be two quasi-nonexpansive multivalued mappings and $\left\{\alpha_{n}\right\},\left\{\beta_{n}\right\},\left\{\gamma_{n}\right\}$ be three real sequences in $[0,1]$ satisfying $\alpha_{n}+\beta_{n}+\gamma_{n}=1,0<a \leq$ $\alpha_{n}$ where $a$ is a constant. Let $\left\{x_{n}\right\}$ be the sequence as defined in (1.3). If $F \neq \varnothing$ and $S p=T p=\{p\}$ for any $p \in F$ then $\lim _{n \rightarrow \infty}\left\|x_{n}-p\right\|$ exists for all $p \in F$. 
Proof. Let $p \in F$. It follows from (1.3) that

$$
\begin{aligned}
\left\|x_{n}-p\right\| & \leq \alpha_{n}\left\|x_{n-1}-p\right\|+\beta_{n}\left\|y_{n}-p\right\|+\gamma_{n}\left\|z_{n}-p\right\| \\
& \leq \alpha_{n}\left\|x_{n-1}-p\right\|+\beta_{n} d\left(S x_{n}, p\right)+\gamma_{n} d\left(T x_{n}, p\right) \\
& \leq \alpha_{n}\left\|x_{n-1}-p\right\|+\beta_{n} H\left(S x_{n}, S p\right)+\gamma_{n} H\left(T x_{n}, T p\right) \\
& \leq \alpha_{n}\left\|x_{n-1}-p\right\|+\beta_{n}\left\|x_{n}-p\right\|+\gamma_{n}\left\|x_{n}-p\right\|
\end{aligned}
$$

and implies that $\left(1-\beta_{n}-\gamma_{n}\right)\left\|x_{n}-p\right\| \leq \alpha_{n}\left\|x_{n-1}-p\right\|$ or $\alpha_{n}\left\|x_{n}-p\right\| \leq \alpha_{n}\left\|x_{n-1}-p\right\|$. Since $\alpha_{n} \geq a>0$, therefore

$$
\left\|x_{n}-p\right\| \leq\left\|x_{n-1}-p\right\| \text {. }
$$

We get that $\left\{\left\|x_{n}-p\right\|\right\}$ is a decreasing sequence, so $\lim _{n \rightarrow \infty}\left\|x_{n}-p\right\|$ exists for each $p \in F$.

Lemma 3. Let $X$ be a uniformly convex Banach space and $E$ be a nonempty closed convex subset of $X$. Let $S, T: E \rightarrow C B(E)$ be two quasi-nonexpansive multivalued mappings and $\left\{\alpha_{n}\right\},\left\{\beta_{n}\right\},\left\{\gamma_{n}\right\}$ be three real sequences in $[0,1]$ satisfying $\alpha_{n}+\beta_{n}+\gamma_{n}=1,0<a \leq \alpha_{n}, \beta_{n}, \gamma_{n} \leq b<1$ where $a, b$ are some constants. Let $\left\{x_{n}\right\}$ be the sequence as defined in (1.3). If $F \neq \varnothing$ and $S p=T p=\{p\}$ for any $p \in F$ then $\lim _{n \rightarrow \infty} d\left(x_{n}, S x_{n}\right)=0=\lim _{n \rightarrow \infty} d\left(x_{n}, T x_{n}\right)$.

Proof. From Lemma 2, $\lim _{n \rightarrow \infty}\left\|x_{n}-p\right\|$ exists for each $p \in F$. We suppose that $\lim _{n \rightarrow \infty}\left\|x_{n}-p\right\|=d$ for some $d \geq 0$. Then

$$
\begin{aligned}
& \lim _{n \rightarrow \infty}\left\|x_{n}-p\right\|=\lim _{n \rightarrow \infty}\left\|\alpha_{n}\left(x_{n-1}-p\right)+\beta_{n}\left(y_{n}-p\right)+\gamma_{n}\left(z_{n}-p\right)\right\| \\
= & \lim _{n \rightarrow \infty}\left\|\left(1-\gamma_{n}\right)\left[\frac{\alpha_{n}}{1-\gamma_{n}}\left(x_{n-1}-p\right)+\frac{\beta_{n}}{1-\gamma_{n}}\left(y_{n}-p\right)\right]+\gamma_{n}\left(z_{n}-p\right)\right\| \\
= & d .
\end{aligned}
$$

Since $T$ is a quasi-nonexpansive mapping and $F \neq \varnothing$, we have

$$
\left\|y_{n}-p\right\|=d\left(y_{n}, S p\right) \leq H\left(S x_{n}, S p\right) \leq\left\|x_{n}-p\right\|
$$

for each $p \in F$. Taking limsup on both sides, we obtain

$$
\limsup _{n \rightarrow \infty}\left\|y_{n}-p\right\| \leq d \text {. }
$$

Similarly,

$$
\limsup _{n \rightarrow \infty}\left\|z_{n}-p\right\| \leq d
$$

Now using (3.1), we have

$$
\begin{aligned}
& \limsup _{n \rightarrow \infty}\left\|\frac{\alpha_{n}}{1-\gamma_{n}}\left(x_{n-1}-p\right)+\frac{\beta_{n}}{1-\gamma_{n}}\left(y_{n}-p\right)\right\| \\
& \leq \limsup _{n \rightarrow \infty}\left[\frac{\alpha_{n}}{1-\gamma_{n}}\left\|x_{n-1}-p\right\|+\frac{\beta_{n}}{1-\gamma_{n}}\left\|y_{n}-p\right\|\right]
\end{aligned}
$$




$$
\begin{aligned}
& \leq \limsup _{n \rightarrow \infty}\left[\frac{\alpha_{n}}{1-\gamma_{n}}\left\|x_{n-1}-p\right\|+\frac{\beta_{n}}{1-\gamma_{n}}\left\|x_{n}-p\right\|\right] \\
& =\limsup _{n \rightarrow \infty}\left\|x_{n-1}-p\right\| \\
& =d .
\end{aligned}
$$

Using (3.2), (3.3), (3.5) and Lemma 1, we get

$$
\lim _{n \rightarrow \infty}\left\|\frac{\alpha_{n}}{1-\gamma_{n}}\left(x_{n-1}-p\right)+\frac{\beta_{n}}{1-\gamma_{n}}\left(y_{n}-p\right)-\left(z_{n}-p\right)\right\|=0 .
$$

This means that

$$
\begin{aligned}
& \lim _{n \rightarrow \infty}\left\|\frac{\alpha_{n}}{1-\gamma_{n}} x_{n}+\frac{\beta_{n}}{1-\gamma_{n}} y_{n}-z_{n}\right\| \\
& =\lim _{n \rightarrow \infty}\left(\frac{1}{1-\gamma_{n}}\right)\left\|\alpha_{n} x_{n}+\beta_{n} y_{n}-\left(1-\gamma_{n}\right) z_{n}\right\| \\
& =0 .
\end{aligned}
$$

Since $0<a \leq \gamma_{n} \leq b<1$, we have $\frac{1}{1-a} \leq \frac{1}{1-\gamma_{n}} \leq \frac{1}{1-b}$. Thus,

$$
\lim _{n \rightarrow \infty}\left\|x_{n}-z_{n}\right\|=0 \text {. }
$$

In a similar way, we can show that

$$
\lim _{n \rightarrow \infty}\left\|x_{n}-y_{n}\right\|=0 \text {. }
$$

Therefore,

$$
d\left(x_{n}, T x_{n}\right) \leq d\left(x_{n}, z_{n}\right)
$$

and

$$
d\left(x_{n}, S x_{n}\right) \leq d\left(x_{n}, y_{n}\right)
$$

gives $d\left(x_{n}, T x_{n}\right)$, and $d\left(x_{n}, S x_{n}\right) \rightarrow 0$ as $n \rightarrow \infty$. This completes the proof of the lemma.

Now, we give some strong convergence theorems. Our first strong convergence theorem is in general real Banach spaces. We then apply this theorem to obtain a result in uniformly convex Banach spaces.

Theorem 1. Let $X$ be a real Banach space and $E,\left\{x_{n}\right\} S, T$ be as in Lemma 3. If $F \neq \varnothing$ and $S p=T p=\{p\}$ for any $p \in F$ then $\left\{x_{n}\right\}$ converges strongly to a common fixed point of $S$ and $T$ if and only if $\liminf _{n \rightarrow \infty} d\left(x_{n}, F\right)=0$.

Proof. The necessity is obvious. Conversely, suppose that $\liminf _{n \rightarrow \infty} d\left(x_{n}, F\right)=0$. From Lemma 2, we know that

$$
\left\|x_{n}-p\right\| \leq\left\|x_{n-1}-p\right\|
$$


which gives

$$
d\left(x_{n}, F\right) \leq d\left(x_{n-1}, F\right) .
$$

This implies that $\lim _{n \rightarrow \infty} d\left(x_{n}, F\right)$ exists and so by the hypothesis, $\liminf _{n \rightarrow \infty} d\left(x_{n}, F\right)=0$. Therefore we must have $\lim _{n \rightarrow \infty} d\left(x_{n}, F\right)=0$.

Now we show that $\left\{x_{n}\right\}$ is a Cauchy sequence in $E$. Let $\varepsilon>0$ be arbitrarily chosen. Since $\lim _{n \rightarrow \infty} d\left(x_{n}, F\right)=0$, there exists a constant $n_{0}$ such that for all $n \geq n_{0}$, we have

$$
d\left(x_{n}, F\right)<\frac{\varepsilon}{4} .
$$

In particular, $\inf \left\{\left\|x_{n_{0}}-p\right\|: p \in F\right\}<\frac{\varepsilon}{4}$. There must exist a $p^{*} \in F$ such that

$$
\left\|x_{n_{0}}-p^{*}\right\|<\frac{\varepsilon}{2}
$$

For $m, n \geq n_{0}$, we have

$$
\begin{aligned}
\left\|x_{n+m}-x_{n}\right\| & \leq\left\|x_{n+m}-p^{*}\right\|+\left\|x_{n}-p^{*}\right\| \\
& \leq 2\left\|x_{n_{0}}-p^{*}\right\| \\
& <2\left(\frac{\varepsilon}{2}\right)=\varepsilon
\end{aligned}
$$

Therefore $\left\{x_{n}\right\}$ is a Cauchy sequence in a closed subset $E$ of a Banach space $E$. So it must converge in $E$. We suppose that $\lim _{n \rightarrow \infty} x_{n}=q$. Now

$$
\begin{aligned}
d(q, S q) & \leq d\left(q, x_{n}\right)+d\left(x_{n}, S x_{n}\right)+H\left(S x_{n}, S q\right) \\
& \leq d\left(q, x_{n}\right)+d\left(x_{n}, y_{n}\right)+d\left(x_{n}, q\right) \\
& \rightarrow 0 \text { as } n \rightarrow \infty
\end{aligned}
$$

gives that $d(q, S q)=0$ which implies that $q \in S q$. Similarly,

$$
\begin{aligned}
d(q, T q) & \leq d\left(q, x_{n}\right)+d\left(x_{n}, T x_{n}\right)+H\left(T x_{n}, T q\right) \\
& \leq d\left(q, x_{n}\right)+d\left(x_{n}, z_{n}\right)+d\left(x_{n}, q\right) \\
& \rightarrow 0 \text { as } n \rightarrow \infty
\end{aligned}
$$

implies that $q \in T q$. Consequently, $q \in F$.

In our next theorem, we assume that $S, T: E \rightarrow C B(E)$ satisfy condition $\left(A^{\prime}\right)$. In contrast to Theorem 3.8 [10], we do not impose the condition of proximinality on $F$. We now apply the above theorem to obtain the following.

Theorem 2. Let $X$ be a uniformly convex Banach space and $E,\left\{x_{n}\right\}$ be as in Lemma 2. Let $S, T: E \rightarrow C B(E)$ be two quasi-nonexpansive multivalued mappings satisfying Condition $\left(A^{\prime}\right)$. If $F \neq \varnothing$ and $S p=T p=\{p\}$ for any $p \in F$ then $\left\{x_{n}\right\}$ converges strongly to a common fixed point of $S$ and $T$. 
Proof. From Lemma $3, \lim _{n \rightarrow \infty}\left\|x_{n}-p\right\|$ exists for all $p \in F$. We suppose that $\lim _{n \rightarrow \infty}\left\|x_{n}-p\right\|=d$ for some $d \geq 0$. If $d=0$, there is nothing to prove. Suppose $d>0$. Now $\left\|x_{n}-p\right\| \leq\left\|x_{n-1}-p\right\|$ gives that

$$
\inf _{p \in F}\left\|x_{n}-p\right\| \leq \inf _{p \in F}\left\|x_{n-1}-p\right\|
$$

which means that $d\left(x_{n}, F\right) \leq d\left(x_{n-1}, F\right)$ and so $\lim _{n \rightarrow \infty} d\left(x_{n}, F\right)$ exists. By using condition $\left(A^{\prime}\right)$, either

or

$$
\lim _{n \rightarrow \infty} f\left(d\left(x_{n}, F\right)\right) \leq \lim _{n \rightarrow \infty} d\left(x_{n}, T x_{n}\right)=0
$$

$\lim _{n \rightarrow \infty} f\left(d\left(x_{n}, F\right)\right) \leq \lim _{n \rightarrow \infty} d\left(x_{n}, S x_{n}\right)=0$.

In both the cases, we have

$$
\lim _{n \rightarrow \infty} f\left(d\left(x_{n}, F\right)\right) \leq \lim _{n \rightarrow \infty} d\left(x_{n}, S x_{n}\right)=0 .
$$

$$
\lim _{n \rightarrow \infty} f\left(d\left(x_{n}, F\right)\right)=0 .
$$

Since $f$ is a nondecreasing function and $f(0)=0$, so it follows that $\lim _{n \rightarrow \infty} d\left(x_{n}, F\right)=$ 0 . Now applying the above theorem, we obtain the result.

Finally, here we will approximate common fixed points of the mappings $S$ and $T$ through the weak convergence of the sequence $\left\{x_{n}\right\}$ defined in (1.3).

Theorem 3. Let $X$ be a uniformly convex Banach space satisfying the Opial's condition and $E, S, T$ and $\left\{x_{n}\right\}$ be as taken in Lemma 3. If $F \neq \varnothing$ and $S p=T p=$ $\{p\}$ for any $p \in F, I-S$ and $I-T$ are demiclosed with respect to zero, then $\left\{x_{n}\right\}$ converges weakly to a common fixed point of $S$ and $T$.

Proof. Let $p \in F$. From the proof of Lemma 2, $\lim _{n \rightarrow \infty}\left\|x_{n}-p\right\|$ exists. Now we prove that $\left\{x_{n}\right\}$ has a unique weak subsequential limit in $F$. To prove this, let $z_{1}$ and $z_{2}$ be weak limits of the subsequences $\left\{x_{n_{i}}\right\}$ and $\left\{x_{n_{j}}\right\}$ of $\left\{x_{n}\right\}$, respectively. By Lemma 3, there exists $y_{n} \in S x_{n}$ such that $\lim _{n \rightarrow \infty}\left\|x_{n}-y_{n}\right\|=0$ and $I-S$ is demiclosed with respect to zero, therefore we obtain $z_{1} \in S z_{1}$. Similarly, $z_{1} \in T z_{1}$. Again in the same way, we can prove that $z_{2} \in F$.

Next, we prove uniqueness. For this, suppose that $z_{1} \neq z_{2}$. Then by the Opial's condition, we have

$$
\begin{aligned}
\lim _{n \rightarrow \infty}\left\|x_{n}-z_{1}\right\| & =\lim _{n_{i} \rightarrow \infty}\left\|x_{n_{i}}-z_{1}\right\| \\
& <\lim _{n_{i} \rightarrow \infty}\left\|x_{n_{i}}-z_{2}\right\| \\
& =\lim _{n \rightarrow \infty}\left\|x_{n}-z_{2}\right\| \\
& =\lim _{n_{j} \rightarrow \infty}\left\|x_{n_{j}}-z_{2}\right\| \\
& <\lim _{n_{j} \rightarrow \infty}\left\|x_{n_{j}}-z_{1}\right\|
\end{aligned}
$$




$$
=\lim _{n \rightarrow \infty}\left\|x_{n}-z_{1}\right\|
$$

which is a contradiction. Hence $\left\{x_{n}\right\}$ converges weakly to a point in $F$.

The compactness assumption is quite strong, since it is easy to find a sequence in the domain which converges to a fixed point of the mapping. Therefore, we give the following result.

Corollary 1. Let $E$ be a nonempty compact convex subset of a uniformly convex Banach space $X$ satisfying Opial's condition, $S, T: E \rightarrow K(E)$ be two quasinonexpansive multivalued mappings where $K(E)$ is the family of nonempty compact subsets of $E$ and $\left\{\alpha_{n}\right\},\left\{\beta_{n}\right\},\left\{\gamma_{n}\right\}$ be three real sequences in $[0,1]$ satisfying $\alpha_{n}+\beta_{n}+\gamma_{n}=1,0<a \leq \alpha_{n}, \beta_{n}, \gamma_{n} \leq b<1$ where $a, b$ are some constants. Let $\left\{x_{n}\right\}$ be the sequence as defined in (1.3). If $F \neq \varnothing$ and $S p=T p=\{p\}$ for any $p \in F$ then $\left\{x_{n}\right\}$ converges weakly to a common fixed point of $S$ and $T$.

The algorithm (1.3) reduces to the algorithm (1.2) when either $S=T$ or $\beta_{n}=0$ or $\gamma_{n}=0$. Therefore, we obtain the following results.

Corollary 2. Let $X$ be a uniformly convex Banach space and $E$ be a nonempty closed convex subset of $X$. Let $T: E \rightarrow C B(E)$ be a quasi-nonexpansive multivalued mapping satisfying Condition $(A)$ and $\left\{\alpha_{n}\right\}$ be a real sequence in $[0,1]$ satisfying $0<a \leq \alpha_{n} \leq b<1$ where $a, b$ are some constants. Let $\left\{x_{n}\right\}$ be the sequence as defined in (1.2). If $F \neq \varnothing$ and $T p=\{p\}$ for any $p \in F$ then $\left\{x_{n}\right\}$ converges strongly to a fixed point of $T$.

Corollary 3. Let $X$ be a uniformly convex Banach space satisfying the Opial's condition and $E$ be a nonempty closed convex subset of $X$. Let $T: E \rightarrow C B(E)$ be a quasi-nonexpansive multivalued mapping and $\left\{\alpha_{n}\right\}$ be a real sequence in $[0,1]$ satisfying $0<a \leq \alpha_{n} \leq b<1$ where $a, b$ are some constants. Let $\left\{x_{n}\right\}$ be the sequence as defined in (1.2). If $F \neq \varnothing$ and $T p=\{p\}$ for any $p \in F, I-T$ is demiclosed with respect to zero, then $\left\{x_{n}\right\}$ converges weakly to a fixed point of $T$.

\section{REFERENCES}

[1] H. Fukhar-Ud-Din and S. H. Khan, "Convergence of iterates with errors of asymptotically quasinonexpansive mappings and applications," J. Math. Anal. Appl., vol. 328, no. 2, pp. 821-829, 2007.

[2] L. Górniewicz, Topological fixed point theory of multivalued mappings, ser. Mathematics and its Applications (Dordrecht). Dordrecht: Kluwer Academic Publishers, 1999, vol. 495.

[3] H. He, S. Liu, and R. Chen, "Mann type implicit iteration approximation for multivalued mappings in Banach spaces," Fixed Point Theory Appl., vol. 2010, p. 8, 2010.

[4] S. H. Khan and H. Fukhar-ud-din, "Weak and strong convergence of a scheme with errors for two nonexpansive mappings," Nonlinear Anal., Theory Methods Appl., Ser. A, Theory Methods, vol. 61, no. 8, pp. 1295-1301, 2005.

[5] S. H. Khan, I. Yildirim, and M. Ozdemir, "Convergence of an implicit algorithm for two families of nonexpansive mappings," Comput. Math. Appl., vol. 59, no. 9, pp. 3084-3091, 2010. 
[6] T.-C. Lim, "A fixed point theorem for multivalued nonexpansive mappings in a uniformly convex Banach space,” Bull. Am. Math. Soc., vol. 80, pp. 1123-1126, 1974.

[7] J. Markin, "Continuous dependence of fixed point sets," Proc. Am. Math. Soc., vol. 38, pp. 545$547,1973$.

[8] S. B. Nadler Jr., “Multivalued contraction mappings,” Pacific J. Math., vol. 30, pp. 475-488, 1969.

[9] Z. Opial, "Weak convergence of the sequence of successive approximations for nonexpansive mappings," Bull. Am. Math. Soc., vol. 73, pp. 591-597, 1967.

[10] B. Panyanak, "Mann and Ishikawa iterative processes for multivalued mappings in Banach spaces," Comput. Math. Appl., vol. 54, no. 6, pp. 872-877, 2007.

[11] D. Sahu, "Strong convergence theorems for nonexpansive type and non-self multi-valued mappings," Nonlinear Anal., Theory Methods Appl., vol. 37, no. 3, pp. 401-407, 1999.

[12] J. Schu, "Weak and strong convergence to fixed points of asymptotically nonexpansive mappings," Bull. Aust. Math. Soc., vol. 43, no. 1, pp. 153-159, 1991.

[13] N. Shahzad and H. Zegeye, "On Mann and Ishikawa iteration schemes for multi-valued maps in Banach spaces," Nonlinear Anal., Theory Methods Appl., Ser. A, Theory Methods, vol. 71, no. 3-4, pp. 838-844, 2009.

[14] S. M. Soltuz, "The backward Mann iteration," Octogon Mathematics Magazine, vol. 9, pp. 797$800,2001$.

[15] H.-K. Xu, "Multivalued nonexpansive mappings in Banach spaces," Nonlinear Anal., Theory Methods Appl., Ser. A, Theory Methods, vol. 43, no. 6, pp. 693-706, 2001.

[16] H.-K. Xu and R. G. Ori, "An implicit iteration process for nonexpansive mappings," Numer. Funct. Anal. Optim., vol. 22, no. 5-6, pp. 767-773, 2001.

Author's address

Isa Yildirim

Department of Mathematics, Faculty of Science, Ataturk University, 25240 Erzurum, Turkey

E-mail address: isayildirimeatauni.edu.tr 